\title{
Satisfaction and Getting a Career: Employment Expectations of Undergraduate Students and Their Use of Support Services
}

\author{
James-MacEachern, Melissa
}

Faculty of Business, University of Prince Edward Island, Canada.

\begin{abstract}
The purpose of this paper is to explore the factors that affect higher education student satisfaction and future employment and their use of career and other support services while attending an institution. The descriptive results of this study suggest that while student satisfaction may be relatively similar for all academic programs, students utilize career and other support services very little. Most notably, the results also indicate students' expectations for employment was not related to their experience issuing these services. On the contrary, they were mostly satisfied with their academic and personal development. In essence, students felt prepared for the workplace based on their academic experiences rather than through other supports offered by the institution. This paper suggests that institutions' efforts are best placed on the academic and learning experience available to their students versus career and support services.
\end{abstract}

Keywords: higher education, satisfaction, career, support services 


\section{Introduction}

Higher education institutions (HEI) and their programs benefit students, but also society as well. One goal for HEIs is to provide students with the skills and knowledge that they need to be successful in society (Bright \& Graham Jr., 2016). HEIs can evaluate institutional performance by exploring and understanding student attitudes and perceptions during and after their educational experience. Education needs to assist students in achieving life goals and as such, it is worthwhile to evaluate the role of HEIs in students' lives (Bright \& Graham Jr., 2016).

It has been argued that the decision to invest in an undergraduate degree is influenced by the ability to achieve higher income upon graduation for the duration of one's career (Elliot, 2002). In a recent US study, it was found that the expectation upon completion of an undergraduate degree is that the student would earn, on average, $10 \%$ more than someone with a high school diploma. This salary expectation and a successful transition to the labour market have been found to be motivators for the growth in degrees around the world (Uhlig, R. P., Mehta, K., Silverstone, S., \& Mossavar-Rahmani, F., 2015). With students apparently making decisions to attend HEIs with expectations of income and employment, it is important for HEIs to understand these expectations before enrolment and throughout the student academic experience.

Other studies of students' opinions on the relationship between their educational experience and employment a few years after graduation include a survey of undergraduates who were at least two years' post-graduation in Spain. The results of this survey indicated that when asked to consider the hypothetical question of repeating their studies, 'graduates clearly place the highest level of importance on the quality of education' (Martínez, and Toledo, 2013, p. 66). In this instance, quality education was measured by theory-based and practicebased education, teaching quality, general academic support, and curriculum design (Martinez and Toledo, 2013). The authors determined that 'the development of competencies and skills and the fitness-for-purpose of studies in relation to the job market are very important dimensions - the latter more so in the choice of studies' (Martínez and Toledo, 2013). The conclusion is that education-to-job fit influenced students' satisfaction level with the area of study they pursued.

Martin et al.'s study on students' satisfaction with their education and how prepared they are for the workplace identified five factors related to satisfaction and workplace preparedness: 1) academic resources such as faculty/staff ratios; 2) faculty/staff attributes including quality of teaching; 3) student access to support resources; 4) curriculum such as breadth and depth of content; and 5) key concepts that related to theory and employment (Martin, Milne-Home, Barrett, Spalding \& Jones, 2000). All of these factors are intrinsically related to the HEI itself and the academic program rather than extrinsic factors 
such as labour market conditions or expectations, indicating that workplace preparedness is important to students, but expectations for employment do not rest with the HEI.

The literature suggests that students' satisfaction is an important factor to consider in terms of successful outcomes from their higher education academic experience. While the previous research points to some determinants of student satisfaction to be related to quality education, quality is a broad term, and students assess quality teaching and education subjectively. Alongside factors such as teaching quality, course content, and perceived skill development, Letcher and Neves identified non-academic factors when evaluating quality, such as extracurricular and experiential opportunities, availability of academic advising and mentorship, and the extent and modernity of institutional technology (Letcher \& Neves, 2010).

\section{Methodology}

This study was conducted at a small-sized (less than 5000 students) higher institution in Canada that primarily provides undergraduate courses. The study was designed to evaluate institutional performance related to students' satisfaction and their preparedness for future employment endeavours. The target population for the survey was 750 degree-seeking undergraduate students registered at the home institution as of Week 3 in the Fall 2015 semester. For the purposes of analysis, only undergraduate data were explored. The survey was implemented over the institutional website via the student portal. Only graduating students were invited to participate. Of the 750 students who were eligible to participate in the survey, 260 responded-a response rate of $34.6 \%$.

\section{Findings: Satisfaction relates to academic experience}

Survey data analysis shows that there was a high degree of student satisfaction with overall institutional experience: $75.6 \%$ of undergraduate students reported that they were 'satisfied' or 'very satisfied' with the overall quality of instruction (Figure 2). Likewise, a majority of students indicated that they were 'satisfied' or 'very satisfied' with the overall academic experiences at the institution at $75.3 \%$, overall university experiences $71.6 \%$ and overall quality of university services and facilities $70.4 \%$. While Business students were more likely to be satisfied with the overall quality of university services and facilities, Nursing students were more likely to be satisfied with the overall quality of instruction, overall academic experience, and overall social life. .

The survey asked students to answer to what extent their goals were achieved (until now) through their educational experience at the institution. Overall, most of the students reported that their goals were achieved at least to some extent. All measuring items were higher than $70 \%$. Nonetheless, the students felt that 'being able to make more money,' 
'getting training for a specific career,' and 'being able to get a good job' were less achieved than other goals. It was found that Nursing students were more likely to feel that their goals were achieved than other undergraduate students. Interestingly, students felt that 'gaining a general education and appreciation of ideas' and 'learning more about things that interest me' scored the highest on perceived goal achievement.

The survey was able to substantiate the students' use of the support services offered by the institution by confirming whether they had actually used such support services. Overall, the results indicated indicate that few students made use of these services with any regularity. Nearly $75 \%$ of students indicated they never used career services, and $15 \%$ occasionally used to very frequently. Used this service. Career services were used most by Business students. The survey also explored the students' expectations of future employment and career, including 'effectiveness of university programs in preparing for employment and career, confidence that they would be able to obtain a paid job related to the current field of study, and expectations of working place and yearly salary'.

As presented in Table 1, regarding the effectiveness of university programs, the vast majority of undergraduate $(85.5 \%)$ reported that the institutional programs and experiences were 'somewhat' or 'very effective' in preparing them for employment and career. In terms of confidence that students would be able to obtain a paid job related to their current field of study, nearly 7 in 10 undergraduate students $(69.7 \%)$ reported that they were 'very' or 'definitely' related. With regard to pursuing a job and the study program, $43.9 \%$ of undergraduate students reported that they were 'very' or 'definitely' confident they would find a job in their field. 


\begin{tabular}{|c|c|c|c|c|c|c|}
\hline \multirow[t]{2}{*}{ Table 1} & \multicolumn{6}{|c|}{ Undergraduate Level } \\
\hline & Arts & Business & Education & Nursing & Science & $\begin{array}{l}\text { Undergrad } \\
\text { Total }\end{array}$ \\
\hline$N$ & 190 & 169 & 75 & 66 & 250 & 750 \\
\hline$\%$ & $25.3 \%$ & $22.5 \%$ & $10.0 \%$ & $8.8 \%$ & $33.3 \%$ & $(77.2 \%)$ \\
\hline Not at all effective & $3.3 \%$ & $3.7 \%$ & $0.0 \%$ & $\mathbf{0 . 0 \%}$ & $5.8 \%$ & $3.6 \%$ \\
\hline Not effective & $1.7 \%$ & $0.0 \%$ & $4.5 \%$ & $0.0 \%$ & $2.1 \%$ & $1.5 \%$ \\
\hline Slightly effective & $6.7 \%$ & $15.2 \%$ & $0.0 \%$ & $0.0 \%$ & $12.4 \%$ & $9.3 \%$ \\
\hline Somewhat effective & $40.0 \%$ & $47.6 \%$ & $59.1 \%$ & $4.5 \%$ & $52.9 \%$ & $44.6 \%$ \\
\hline Very effective & $48.3 \%$ & $33.5 \%$ & $36.4 \%$ & $95.5 \%$ & $26.9 \%$ & $40.9 \%$ \\
\hline Mean Value ${ }^{\text {b) }}$ & 4.28 & 4.08 & 4.27 & 4.95 & 3.93 & 4.18 \\
\hline Not at all confident & $7.0 \%$ & $1.8 \%$ & $4.2 \%$ & $0.0 \%$ & $9.3 \%$ & $5.6 \%$ \\
\hline Not very confident & $11.1 \%$ & $10.2 \%$ & $20.8 \%$ & $4.6 \%$ & $18.2 \%$ & $13.7 \%$ \\
\hline Somewhat confident & $49.1 \%$ & $34.9 \%$ & $33.3 \%$ & $0.0 \%$ & $40.3 \%$ & $36.8 \%$ \\
\hline Very confident & $29.2 \%$ & $33.1 \%$ & $25.0 \%$ & $40.0 \%$ & $22.0 \%$ & $28.3 \%$ \\
\hline Definitely confident & $3.5 \%$ & $19.9 \%$ & $16.7 \%$ & $55.4 \%$ & $10.2 \%$ & $15.6 \%$ \\
\hline Mean Value ${ }^{\text {b) }}$ & 3.11 & 3.60 & 3.29 & 4.45 & 3.06 & 3.35 \\
\hline Not at all related & $7.2 \%$ & $1.8 \%$ & $0.0 \%$ & $0.0 \%$ & $7.9 \%$ & $4.8 \%$ \\
\hline Not very related & $0.0 \%$ & $0.0 \%$ & $0.0 \%$ & $0.0 \%$ & $0.0 \%$ & $0.0 \%$ \\
\hline Somewhat related & $38.9 \%$ & $29.9 \%$ & $8.3 \%$ & $0.0 \%$ & $25.6 \%$ & $25.6 \%$ \\
\hline Very related & $35.3 \%$ & $44.9 \%$ & $20.8 \%$ & $25.4 \%$ & $32.6 \%$ & $34.3 \%$ \\
\hline Definitely related & $18.6 \%$ & $23.4 \%$ & $\mathbf{7 0 . 8 \%}$ & $74.6 \%$ & $33.9 \%$ & $35.4 \%$ \\
\hline Mean Value b) & 3.57 & 3.88 & 4.63 & 4.75 & 3.84 & 3.95 \\
\hline
\end{tabular}




\section{Discussion}

These findings support previous research related to student satisfaction. Student satisfaction appears to be most strongly related to educational and academic experience while at a higher educational institution (Astin, 1984; Elliot, 2002; Douglas et. al, 2008; Mark, 2013). While other studies suggest that it is critical to link graduate employability to student satisfaction, this study supports the case that although these two factors are important considerations for HEIs, they are not necessarily indicative of students' perceptions of higher education satisfaction while in attendance at the institution.

Students place value on academic study and knowledge development, albeit they think about employment, but their attitudes and perceptions regarding their HEI experience relate to a broad range of learning experiences in higher education. Social network building, development as a critical thinker, learning on- and off-campus, cultural understanding, and generally becoming a more grounded person responsible for the community are viewed as important outcomes in their academic experience (Cranmer, 2006, Crossman \& Clark, 2010, Barnett, 2011).

This study found all cohorts ranked 'gaining a general education and appreciation of ideas' as the top goal achieved in their academic experience followed by 'learning more about things that interest me.' All cohorts other than Nursing and Education students ranked career and financial goals lower. This may be a result of Education and Nursing being professional programs with preparation for employment embedded in their higher education experience. As a result, both cohorts may feel prepared for employment with specific income expectations being attainable.

However, students place a sizable importance on the current and future labour market at the time of choosing their area of study, in the hope that when they reach graduation, they will be able to find employment in their area of study (Martinez \& Toledo, 2013). Student motivation to attend HEIs and student expectations related to labour market expectations are important factors to consider in terms of meeting student expectations and needs.

Overall academic experience and quality of instruction were the most important factors in student satisfaction ranking for this HEI. Students in this study indicate they believe their program was effective in preparing them for employment. However, they were less confident they would obtain a job in their field even though they were pursuing work in this area. It is interesting to note that these students believe the institution was effective in preparing them for the labour market, but their expectations of success in finding a job in the field were much lower. This would indicate the students perceive that the institution is doing its 'job' in preparing students for the labour market, but there is less confidence in what is available for employment. This also shows that students are aware that the labour market operates with specific rules that cannot be neatly translated into HE responsibility. 
This 'fitness-for-purpose' is important so that HEIs, at least in the context of this study, which is Canada, continue to evaluate and enhance academic experiences so that they are satisfactory and relevant to students. Yet, if the educational system is too concerned with research outcomes and developments and places less importance in rewarding staff teaching engagement, this is problematic and may result in burdened and stressed academic staff.

Nearly $75 \%$ of the respondents in this survey indicated they never used career services during their undergraduate degree, but they were still satisfied with their HE experience. This suggests that in the Canadian context, students are seeking 'an education,' and an educational experience, and not merely a ticket to employability (Molesworth, et. al., 2009). However, the Canadian Chamber of Commerce suggests that mandatory informed career counseling services for students be implemented and suggest possible labour market benefits that would result from the successful implementation of such a career counseling services (Canadian Chamber of Commerce, 2015). It is believed the availability of labour market information can impact transition to the labour market for HE students. It was found that this availability of labour market information varied among different countries and, as such, impacted student reliance on various information sources. For example, in the United States and Canada, labour market information is surveyed, updated, and published on a regular basis, which provides continuous access to relevant information for students when making career and educational choices, Hence, it is up to students to decide to what extent this affects their choice. These resources are not available to students in many other countries. As a result, students tend to place a lesser importance on the assistance provided by guidance counselors (for example) in Canada and the United States as they can research trends in their area of study interest (Pitan \& Olugbenga, 2014).

Many factors were found to impact student satisfaction in this study; however, income and labour market expectations did not appear to influence satisfaction. Students found themselves ready and effectively prepared for the labour market, with relatively realistic expectations of income. These findings are consistent with early studies that indicated that satisfaction is not directly linked to labour market readiness (Field, Holley, \& Armenakis, 1974). However, given the demand for professional programs and the high satisfaction of those in professional programs, it is important for HEIs to be aware of student decisionmaking in choosing a program and how expectations and satisfaction evolve over time. 


\section{Conclusion}

This paper explored the subject of satisfaction and career supports for undergraduate students. The findings of this research support those of previous studies related to student satisfaction and support, the importance of quality of instruction (teaching and learning approaches and strategies), and academic experiences in satisfying students (Bright \& Graham Jr., 2016; Field, Holley, \& Armenakis, 1974; Martin, Milne-Home, Barrett, Spalding, \& Jones, 2000). These findings are consistent with research related to employment after graduation/preparation for employment, in that all cohorts felt prepared for employment as a result of their degree, but their expectations of the labour market were mixed due to labour market demand and realities versus the role of (or lack thereof) of HEIs in career preparation (Dragan \& Ivana, 2015; Martin, Milne-Home, Barrett, Spalding, \& Jones, 2000). This study is useful for HEIs' administrators, faculty, and staff, and those who explore methods to focus more on the value and improvement of teaching and learning at HEIs when it comes to students' satisfaction. It appears this satisfaction is linked more to those characteristics of academic and social development related to HEIs than what the HEI was doing to make students 'employable.' The findings challenge the justification of HEIs' 'employability' agenda in order to satisfy students' requirements and needs, and, consequently, satisfaction. They show that students are attending higher education for reasons that are more educational, holistic, personal, and social rather than 'finding a job,'. What this means is that students show an understanding that HE cannot and need not be governed by market rules.

Finally, students' motivation to attend higher education and to generate meaningful employment from their degree appears to be inherently embedded in society. A review of the literature and survey data indicates that students place significant value on teaching and learning as it relates to satisfaction. As a result, students may be satisfied with their undergraduate experience regardless of their expectation for employment. In essence, they felt prepared for the workplace and satisfied with the skills and knowledge they developed at university, regardless of job expectations. This study provides insight into student satisfaction and can assist HEIs in developing policies related to student retention and success. HEIs may find this study useful in developing policies and programs related to transitioning from undergraduate studies to the workplace. 


\section{References}

Astin, A. W. (1984). Student involvement: A developmental theory for higher education. Journal of College Student Personnel, 25(4), 297-308.

Bright, L., \& Graham Jr., C. B. (2016). Predictors of graduate student satisfaction in public administration programs. Journal of Public Affairs Education, 22(1), 17-34.

Barnett, R. (2011). Life-wide education: A new and transformative concept for higher education? In Enabling a more complete education: Encouraging, recognizing and valuing life-wide learning in higher education, ed. N.S. Jackson and R.K. Law, online at http://lifwidelearningconference.pbworks.com/e-proceedings

Canadian Chamber of Commerce (2015). How good is Canada's labour market information? (May 2015)

Cranmer, S. (2006). Enhancing graduate employability: Best intentions and mixed outcomes. Studies in Higher Education, 31(2), 169-184.

Crossman, J.E., Clark, M. (2010). International experience and graduate employability: stakeholder perceptions on connection. Higher Education, 59(50), 599-613.

Douglas, J., McClelland, R. and Davies, J. (2008). The Development of a Conceptual Model of Student Satisfaction with the Experience in Higher Education, Quality Assurance in Education, 16(1) pp. 19-35.

Dragan, M., \& Ivana, D. (2015). Graduates' satisfaction towards service quality in higher education: an empirical investigation. Managerial Challenges in the Contemporary Society, 8(2), 34-38.

Elliot, K. (2002). Key determinants of student satisfaction. Journal of College Student Retention, 4(3), 271-279.

Field, H., Holley, W., \& Armenakis, A. (1974). Graduate students' satisfaction with graduate education: intrinsic versus extrinsic factors. The Journal of Experimental Education, 43(2), 8-15.

Letcher, D. W., \& Neves, J. S. (2010). Determinants of undergraduate business student satisfaction. Research in Higher Education Journal, 6, 1. 401 - 410.

Mark, Eddie (2013). Eddie Mark. Student satisfaction and the customer focus in higher education. Journal of Higher Education Policy and Management 35(1), 2-10.

Martin, A., Milne-Home, J., Barrett, J., Spalding, E., \& Jones, G. (2000). Graduate satisfaction with university and perceived employment preparation. Journal of Education and Work, 13(2), 199-213.

Martinez, T. L., \& Toledo, L. D. (2013). What do Graduates Think? An analysis of intention to repeat the same studies and university. Journal of Marketing for Higher Education, 23(1), 62-89. dx.doi.org/10.1080/1360080X.2012.727703

Molesworth, M, Nixon, E., Scullion, R. (2009). Having, being and higher education: the marketisation of the university and the transformation of the student into consumer. Teaching in Higher Education, 14 (3), 277-287.

Pitan, O. S., \& Olugbenga Adedeji, S. (2014). Students' choice of courses: Determining factors, sources of information, and relationship with the labour market demands in Nigeria. Africa Education Review, 11(3), 445-458. doi:10.1080/18146627.2014.934997 
Uhlig, R. P., Mehta, K., Silverstone, S., \& Mossavar-Rahmani, F. (2015). The value of business education: A case study of business graduates at a large university. Journal of Business Behavioral Sciences, 27(1), 89-106.

Woodall, T., Hiller, A., Resnick, S. (2014). Making sense of higher education: Students as consumers and the value of the university experience. Studies in Higher Education, 39(1), 48-67. 